\title{
PENERAPAN TERAPI WICARA KONSONAN B/P/M/W UNTUK ANAK \\ LAMBAT BICARA USIA 4 TAHUN
}

\section{Inna Hamida Zusfindhana}

Prodi PLB, IKIP PGRI Jember

naahamida@gmail.com

\begin{abstract}
Abstrak
Penelitian ini dilatarbelakangi oleh kondisi objektif anak yang mengalami keterlambatan bicara. Terapi wicara adalah salah satu cara untuk mengatasi masalah tersebut. Terapi wicara dalam penelitian ini di fokuskan dalam pembentukan konsonan $\mathrm{b} / \mathrm{p} / \mathrm{m} / \mathrm{w}$. Tujuan dari penelitian ini untuk meningkatkan kemampuan bicara anak usia empat tahun. Metode yang digunakan dalam penelitian ini adalah metode kualitatif menggunakan observasi dan wawancara untuk menggali data anak dengan keterlambatan bicara. Subjek penelitian merupakan anak lambat bicara usia empat tahun yang berjumlah satu orang. Hasil penelitian menunjukkan bahwa: 1) Perkembangan bahasaan bicara pada tahap ekolalia, 2) Terapi wicara melalui tahapan visual, auditoris, dan haptik, 3) Melalui tahapan visual dan haptik RM mampu mengucapkan dua sampai tiga suku kata, 4) Tahapan haptik RM tidak mengalami masalah.
\end{abstract}

Kata kunci: terapi wicara konsonan b/p/m/w, lambat bicara, usia 4 tahun

\section{PENDAHULUAN}

Keterampilan

berbahasa

merupakan kemampuan pertama dan utama yang harus dimiliki anak. Melalui bahasa anak akan dapat mengeksplorasi berbagai hal yang ada disekitarnya serta menjadi modal utama anak untuk mengembangan berbagai potensi yang ada di dalam dirinya. Pada masa lima tahun pertama yang disebut dengan usia keemasan merupakan masa emas bagi perkembangan anak

Bahasa anak berkembang secara signifikan dari usia 0-7 tahun melalui beberapa tahapan perkembangan bahasa yang disesuaikan dengan usia anak. 
Menurut teori Lev Vygotsky, dari rentang usia tersebut anak akan melewati 4 tahapan perkembangan bahasa meliputi primitive speech stage, naive psycologcal speech stage, egocentris speech stage dan ingrowth speech stage. Teori Vygotsky menekankan bahasa pada kemampuan bicara atau "Speech" yang pada akhirnya akan berkaitan dengan kemampuan berpikir atau "Though". Pada tiap tahapan perkembangan tersebut ada kemampuan berbahasa yang harus dimiliki anak. Anak usia 3-4 tahun berada pada tahap perkembangan egocentris speech stage. Pada tahapan ini kemampuan berbahasa anak yang dapat diamati berupa anak dapat bertanya dan menjawab petanyaan apa, siapa, dimana serta kata tanya lain yang belum membutuhkan penjelasan seperti kata tanya mengapa dan bagaimana.

Menurut Sardjono (2007, hlm. 26) pada usia 3,4-4,5 tahun terjadi aspek-aspek bahasa secara cepat dan kontinyu, perkembangan tanggapan dan perbendaharaan kata semakin banyak melebihi kemampuan artikulasinya. Namun masih memakai subtitusi artikulasi yang belum jelas.

Perkembangan bahasa anak sendiri menurut Santrock (2002, hlm. 178) dibagi ke dalam tahapan sebagai berikut:

1. Tahap Penyuaraan Refleks (reflexive vocalization)

Seluruh aktifitas bayi yang baru lahir hinggga umur tiga minggu masih bersifat refleks, benar-benar tidak disadari, tanpa kehendak, tidak meminta atau menuntut apapun, dan bukan sedang menanggapi rangsangan, misalnya tangisan dan suaranya. Setelah umur empat minggu barulah tangisan atau suaranya mulai berbeda. Hal ini bukan berarti bayi sudah bisa membedakan setiapa rangsangan yang datang kepadanya tetapi masih tetap merupakan refleks, misalnya tangis bayi saat lapar berbeda dengan saat pipis, berbeda lagi dengan tangisan bayi merasa kedinginan.

\section{Tahap Babling}


Umumnya ini terjadi saat bayi berumur 6-7 minggu. Pada masa ini bayi senang mengulang-ulang bunyi yang dibuatnya, yang juga masih tergolong refleks. Bunyi yang dihasilkan mulai bervariasi, pada mingguminggu selanjutnya mulai terdengar bunyi-bunyi konsonan seperti p,b,g dan konsonan sengau (nasal) seperti n. Bunyi-bunyi itu sering dikombinasikan dengan vokal, sehingga terdengar "pa pa pa pa”, ba ba ba" dan "en en en".

3. Tahap Lalling

Tahap ini disebut juga tahap mengoceh atau jargon, umumnya dimulai saat bayi berumur 6-8 bulan. Tahap lalling ini hampir sama dengan tahap babling, perbedaannya terletak pada bentuk ocehan yang dihasilkan. Pada tahap lalling, ocehan sudah merupakan perpaduab beberapa konsonan dan vokal, contoh mam, mam, mam dan gub,gub,gub. Selain itu tahap lalling ini bukan lagi merupakan refleks, melainkan sudah merupakan gerakan yang disadari dan terkoordinasi. Bayi sudah memiliki feedback auditory atau kemampuan menanggapi apa yang didengar. Bayi juga sedang berlatih dengan sengaja untuk mengucapkan kata-kata.

\section{Tahap Ekolalia}

Terjadi pada usia 9-10 bulan, pada tahap ini anak cenderung mengulang atau meniru suku kata yang diucapkan oleh orang lain tanpa mengubahnya. Upaya meniru juga disertai dengan penggunaan gestures atau isyarat gerakan tangan. Penggulangan kata belum disertai dengan pemahaman makna.

\section{Tahap True Speech}

Tahap ini merupakan tahap perkembangan bahasa terakhir. Tahap ini sering juga disebut sebagai tahap 
bicara benar atau first word atau kata pertama, umumnya terjadi saat anak berusia 9-10 bulan

Hasil studi pendahuluan yang dilakukan di Laboratorium PLB IKIP PGRI Jember, diperoleh data tentang anak dengan keterlambatan berbicara. Kemampuan membeo anak sudah cukup baik meskipun bisa mengucapkan satu suku kata awal atau belakangnya saja. Selain itu anak juga masih mengalami hambatan dalam pengucapan konsonan b/p/m/w. Kemampuan berbahasa dan berbicara RM seperti anak usia satu tahun atau tahapan ekolalia. RM tidak merespon keadaan sekitarnya di karenakan anaknya cukup aktif ketika bermain.

Menurut Sardjono (2007, hlm. 147) terapi wicara adalah usaha perbaikan bicara dengan jalan memberkan kebiasaan latihan yang baik. Fungsi dari terapi wicara yaitu membantu anak-anak yang mempunyai hambatan dalam bicara supaya mampu berbicara dengan baik. Selain itu agar anak mampu memiliki dasar ucapan yang benar dan membentuk bunyi bahasa (vokal dan konsonan) dengan benar.

Dasar dalam terapi wicara yaitu melalui pembentukan fonem-fonem, dasar ucapan, proses pembentukan, kesalahan-kesalahan ucapan yang terjadi pada umumnya dan cara melatih serta memperbaikinya. Alatalat yang dibutuhkan ntuk terapi wicara yaitu, kaca besar, spatel, dan berbagai macam permainan untuk anak. Alat-alat permainan anak adalah sebagai berikut:

1. Balon, untuk latihan meniup dan menguatkan daya hembusan

2. Lilin, untuk meniup dan menguatkan otot perut.

3. Kartu nama yang berisi gambar yang ada di sekeliling anak.

4. Miniatur hewan, alat-alat rumah tangga, untuk merangsang komunikasi anak.

Tujuan penelitian ini untuk memperoleh gambaran mengenai masalah keterlambatan bicara dan manfaat terapi wicara dengan konsoan $\mathrm{b} / \mathrm{p} / \mathrm{m} / \mathrm{w}$. 


\section{METODE}

Penelitian ini menggunakan metode kualitatif deskriptif. Metode deskriptif bertujuan untuk mengungkap data-data di lapangan yang bersifat aktual mengenai kondisi objektif anak dalam meminimalisir keterlambatan bicara pada anak. Bertujuan untuk menggali data mengenai kondisi objektif anak, menggunakan aspek-aspek yang terdapat dalam perkembangan bicara anak.

Adapun subjek penelitian ini adalah anak empat tahun yang berjumlah satu orang. Data yang sudah terkumpul tersebut dianalisis kemudian dijadikan sebagai dasar dalam merumuskan program terapi wicara konsonan $\mathrm{b} / \mathrm{p} / \mathrm{m} / \mathrm{w}$ untuk anak lambat bicara.

Penelitian ini menggunakan teknik observasi, wawancara, dan audiovisual atau dokumentasi. Observasi dilakukan untuk melihat dan mencatat perkembangan bicara anak. Proses wawancara di lakukan dengan wawancara secara terstruktur kepada orang tua yang didalamnya menyajikan pertanyaan-pertanyaan secara sistematis yang sesuai dengan tujuan penelitian. Dokumentasi atau audiovisual yang terdiri dari gambar, suara dan video yang dikumpulkan oleh peneliti untuk membantu memahami merekam data yang digunakan. Waktu yang digunakan dalam pelaksanaan penelitian ini selama 60 menit selama 12 kali pertemuan dalam satu bulan.

Teknik analisis data dalam penelitian menggunakan tiga langkah, menurut Milles dan Huberrman yaitu reduksi data, display data, dan verifikasi data. Sedangkan pengujian kredibilitas data diperlukan untuk pengecekkan data yang dilaporkan dengan data yang ditemui di lapangan. (Creswell, 2012).

Pertama, peneliti menganalisis data dengan melakukan reduksi data. Reduksi data berarti merangkum, memilih hal-hal yang pokok, memfokuskan pada hal-hal yang penting. Kemudian peneliti mengadakan penarikan kesimpulan dan pengambilan tindakan.

Kedua, yaitu membuat rangkuman temuan penelitian berdasarkan pada aspek-aspek yang diteliti. Berdasarkan display data, data tersebut akan terorganisasi, 
tersusun dalam pola hubungan, sehingga dapat memudahkan memahami gambaran keseluruan dari aspek-aspek yang diteliti.

Ketiga, yaitu verifikasi data dengan cara mempelajari kembali data-data yang terkumpul dan menarik kesimpulan sehingga mendapatkan temuan baru.

\section{HASIL DAN PEMBAHASAN}

Berdasarkan hasil observasi diperoleh data bahwa kemampuan bicara RM masih dalam tahapan ekolalia atau membeo. RM mampu mengikuti satu suku kata yang di ucapkan. Kemampuan RM yang lain seperti motorik, kognitif, emosi dan sosial tidak mengalami hambatan.

Berdasarkan hasil wawancara dengan orang tua, RM merupakan anak yang sangat aktif. Kemampuan RM selain bahasa sama dengan anak pada umumnya. Orang tua baru menyadari RM mengalami keterlambatan bicara ketika ia berusia tiga tahun. Orang tua sama-sama sibuk, sehingga RM ketika ditinggal orang tuanya bekerja dititipkan ke rumah saudara. Hal ini menyebabkan RM mengalami kurangnya stimulasi komunikasi oleh orang tuanya. Intensitas komunikasi RM sangatlah kurang, karena RM dianggap diam ketika ia bermain sendiri.

Hasil pelaksanaan terapi wicara konsonan $\mathrm{p} / \mathrm{b} / \mathrm{m} / \mathrm{w}$ menunjukkan beberapa hasil :

1. Konsonan /p/

Dasar ucapan fonem /p/ menurut Sardjono (2007, hlm. 163) adalah kedua bibir atas dan bawah. Sedangkan untuk pembentukanya yaitu kedua bibir mengatup rapat, otot tegang sehingga menghambat aliran udara lewat mulut, pipi tegang tetapi tidak cembung, letak lidah datar.

a. Visual

1) Mengajak $\mathrm{RM}$ memperhatikan bentuk bibir peneliti pada cermin

2) Menunjukkan gambar "perahu"

3) Mengucapkan kata "perahu” , "papa” kemudian RM menirukan

4) Mengucapkan pa, po, pi, pu, pe 
Helper, Vol 35 No 1 (2018) - 25

5) Mengucapkan suku kata $\mathrm{Pa}$ pa papa paaaaaaaaa papa papa papa pa pa pa

b. Auditoris

1) Menggunakan suara yang lebih keras

2) mengajak RM merasakan getaran sambil meraban

3) Ketika RM bereaksi ada bunyi, ucapkan kata kemudian anak menirukannya

4) Membiarkan RM meraban sendiri sambil merasakan suaranya.

c. Haptik

1) Mengajak RM untuk merasakan udara meletup yang keluar dari mulut dengan ujung jari.

2) Melakukan latihan pernapasan dengan cara meniup lilin.

Berdasarkan terapi wicara konsonan /p/, untuk kata "papa" RM mampu menirukan dua suku kata tersebut. Kata "perahu” RM mampu menirukan suku kata terakhir yaitu "hu". Penerapan auditoris maupun haptik RM tidak mengalami kesulitan.

\section{Konsonan /b/}

Dasar ucapan fonem /b/ menurut Sardjono (2007, hlm. 166) adalah kedua belah bibir. Pembentukan fonem /b/ yaitu posisi bibir bawah dan atas saling menekan, posisi lidah mendatar, gigi atas dan bawah tidak saling bersentuhan, pita suara bergetar, aliran udara terhambat di dalam rongga mulut.

a. Visual

1) Mengajak $\mathrm{RM}$ memperhatikan bentuk bibir peneliti pada cermin

2) Menunjukkan gambar bola dan baju

3) Mengucapkan kata "bola" , "baju" kemudian RM menirukan

4) Mengucapkan ba, bo, bi, bu, be 
5) Mengucapkan suku kata ba ba baba baaaaaaaaaa bapa baba baba ba ba ba

b. Auditoris

1) Menggunakan suara yang lebih keras

2) Mengajak RM merasakan getaran sambil meraban

3) Ketika RM bereaksi ada bunyi, ucapkan kata kemudian anak menirukannya

4) Membiarkan RM meraban sendiri sambil merasakan suaranya.

c. Haptik

1) Mengajak RM untuk merasakan udara meletup yang keluar dari mulut dengan ujung jari.

2) Melakukan latihan pernapasan dengan cara meniup lilin.

Berdasarkan terapi wicara konsonan /b/, untuk kata "bola" RM mampu menirukan kata "ola". Untuk kata "baju"
RM mampu menirukan suku kata terakhir yaitu "aju". Penerapan auditoris maupun haptik RM tidak mengalami kesulitan

3. Konsonan $/ \mathrm{m} /$

Dasar ucapan fonem $/ \mathrm{m} /$ menurut Sardjono (2007, hlm. 168) adalah kedua bibir atas dan bawah. Pembentukan fonem $/ \mathrm{m} /$ yaitu kedua bibir mrngatup tapi tidak sengau, gigi atas dan bawah tidak bertemu. Getaran di pipi, hidung, telinga, dan leher serta pipi tidak cembung.

a. Visual

1) Mengajak $\mathrm{RM}$ memperhatikan bentuk bibir peneliti pada cermin

2) Menunjukkan gambar mata dan mama

3) Mengucapkan kata "mama", "mata" kemudian $\quad \mathrm{RM}$ menirukan

4) Mengucapkan suku kata ma, mo, mi, mu, me, ma ma mama maaaaaaaaa mama 
mama mama ma ma ma

b. Auditoris

1) Menggunakan suara yang lebih keras

2) Mengajak $\mathrm{RM}$ merasakan getaran sambil meraban

3) Ketika RM bereaksi ada bunyi, ucapkan kata kemudian anak menirukannya

4) Membiarkan $\mathrm{RM}$ meraban sendiri sambil merasakan suaranya.

c. Haptik

1) Mengajak anak untuk merasakan getaran pada bibir, leher, pipi, dan dada.

2) Memberi latihan mengunyah dengan bibir rapat/ latihan mengumam

3) Meakukan latihan pernapasan dengan menghirup dan meniup kapas melalui hidung.
Berdasarkan terapi wicara konsonan /m/, untuk kata "mama" RM mampu menirukan dua suku kata tersebut. Kata "mata" RM mampu menirukan dua suku kata tersebut. Penerapan auditoris maupun haptik RM tidak mengalami kesulitan.

4. Konsonan /w/

Dasar ucapan fonem $/ \mathrm{m} /$ menurut Sardjono (2007, hlm. 171) adalah kedua bibir atas an bawah. Pembentukan fonem /w/ adalah kedua bibir mengatup rapat tetapi saling menekan udara keluar melalui celah sempit antara bibir atas dan bibir bawah dan pita suara bergetar.

a. Visual

1) Mengajak $R M$ memperhatikan bentuk bibir peneliti pada cermin

2) Menunjukkan gambar wortel

3) Mengucapkan kata "wortel"," kemudian RM menirukan 
4) Mengucapkan suku kata wa, wo, wi, wu, we wa wa wawa waaaaaaaaaa wawa wawa wawa wa wa wa

b. Auditoris

1) Menggunakan suara yang lebih keras

2) Mengajak RM merasakan getaran sambil meraban

3) Ketika RM bereaksi ada bunyi, ucapkan kata kemudian anak menirukannya

4) Membiarkan $\mathrm{RM}$ meraban sendiri sambil merasakan suaranya.

c. Haptik

1) Mengajak RM untuk merasakan getaran pada bibir, leher, pipi, dan dada.

2) Melakukan latihan pernapasan dengan menarik nafas, meniup panjang atau pendek.

Berdasarkan terapi wicara konsonan /w/, untuk kata "wortel" RM mampu menirukan kata "otel". Penerapan auditoris maupun haptik RM tidak mengalami kesulitan.

Setelah dilakukan terapi wicara konsonan $\mathrm{p} / \mathrm{b} / \mathrm{m} / \mathrm{w}$ selama satu bulan dengan 12 kali pertemuan RM bisa merespon atau membeo kata-kata yang diucapkan oleh terapis. Selain menggunakan metode visual, auditoris, dan haptik, peneliti juga menggunakan media lagu anak-anak yang disukai RM. Sehingga kosa kata RM semakin berkembang. RM mulai senang mengikuti lagu-lagu yang ditunjukkan oleh peneliti. RM bisa mengucapkan dua sampai tiga suku kata yang jelas artikulasinya.

\section{SIMPULAN}

Berdasarkan hasil dan pembahasan penelitian mengenai terapi wicara konsonan $\mathrm{p} / \mathrm{b} / \mathrm{m} / \mathrm{w}$ diperoleh bahwa RM mengalami keterlambatan bicara, kemampuan Bahasa dan bicaranya berada dalam tahapan anak usia 1-1,5 tahun. Perkembangan bicara dan bahasa berada dalam tahapan ekolalia atau membeo. Hal ini terbukti dari kondisi 
bicara RM yang bisa mengucapkan dua suku kata. Sehingga untuk mengatasi hal tersebut disusunlah program terapi wicara konsoanan $\mathrm{p} / \mathrm{b} / \mathrm{m} / \mathrm{w}$, karena konsonan tersebut merupakan konsonan dasar dalam terapi wicara. Terapi wicara dilakukan melalui tahapan visual, auditoris dan haptik. Selain itu juga menggunakan media musik anakanak. Melalui terapi wicara ini RM bisa mengucapkan dua sampaitiga suku kata. Selain itu RM mulai bisa menyanyikan lagu anak-anak meskipun pengucapannya masih belum jelas. Jadi, terapi wicara tidak hanya dilakukan oleh terapis atau peneliti tetapi juga membutuhkan kerjasama orang tua dalam mestimulasi perkembangan bicara maupun bahasanya agar mencapai tujuan yang optimal.

\section{DAFTAR PUSTAKA}

Creswell, J. (2012). Educational Research: Planning, Conducting, and Evaluating Quantitative and Qualitative Research. Boston: Pearson.

Hurlock, E.B (2002). Psikologi Perkembangan: 5th Edition. Jakarta: Erlangga.

Santrock, John W. (2007). Perkembangan Anak (Jilid 1). Jakarta: Erlangga.

Sardjono. (2007). Terapi Wicara. Jakarta: Departemen Pendidikan Nasional 
Helper, Vol 35 No 1 (2018) - 30 